\title{
Correction to: Development of methodology to generate, measure and characterize the chemical composition of oxidized mercury nanoparticles
}

\author{
Avik. J. Ghoshdastidar ${ }^{1}$ - Janani Ramamurthy ${ }^{1} \cdot$ Maxwell Morissette ${ }^{1}$ - Parisa A. Ariya ${ }^{1,2}$
}

Published online: 16 January 2020

(C) Springer-Verlag GmbH Germany, part of Springer Nature 2020

\section{Correction to: Analytical and Bioanalytical Chemistry} https://doi.org/10.1007/s00216-019-02279-y

The authors would like to call the reader's attention to the fact that, unfortunately, there was an unintentional oversight regarding the funding information in this manuscript; please find the correct information below.

Funding information This study received financial support from the Natural Sciences and Engineering Research Council of Canada (NSERC), HydroQuébec, the Canadian Foundation for Innovation (CFI), Le Fonds de recherche du Québec - Nature et technologies (FRQNT), Environment and Climate Change Canada, McGill University, and the Walter C. Sumner Foundation."

Publisher's note Springer Nature remains neutral with regard to jurisdictional claims in published maps and institutional affiliations.

The online version of the original article can be found at https://doi.org/ 10.1007/s00216-019-02279-y

Parisa A. Ariya

parisa.ariya@mcgill.ca

1 Department of Chemistry, McGill University, 801 Sherbrooke St. West, Montreal H3A 2K6, Canada

2 Department of Atmospheric and Oceanic Sciences, McGill University, 805 Sherbrooke St. West, Montreal H3A 0B9, Canada 